\title{
The problems of young disabled people in St. Petersburg: sociological analysis
}

\section{O. A. Novozhilova ${ }^{1}$}

1Saint Petersburg State University, 7-9 Universitetskaya embankment, Saint Petersburg 199034, Russian Federation

DOI: $10.18255 / 2412-6519-2021-1-76-87$

Research Article

Full text in Russian

Disability as a social problem is one of the most pressing phenomena of modern Russian society. The article analyzes young disabled people as a specific social group and the problems they face in their lives. Young disabled people are quite an active social group, they participate in youth activities, reveal their talents. But because of the barriers in the environment, they cannot fully realize themselves. A study has been carried out showing the problems of young people with disabilities that need to be addressed immediately. Problems such as access to health services and medicines, employment problems, lack of equipment and lack of barrier-free environment, education and information accessibility have been identified. Particular attention is paid to the issue of accessibility as one of the factors preventing young people with disabilities from interacting actively with the environment. The longitudinal nature of the study allowed us to analyze what has changed in solving the problems of this social group. The results of the study showed that in St. Petersburg and other cities, much more attention to this category of people began to be paid, but often problem-solving is still point-by-point rather than complex.

Keywords: disability; young people with disabilities; social policy; people with disabilities; social problem; social group; accessible environment

INFORMATION ABOUT THE AUTHORS

Novozhilova, Olga A. | E-mail: splinter91@mail.ru

For citation: Novozhilova O. A. The problems of young disabled people in St. Petersburg: sociological analysis // Social'nye i gumanitarnye znanija. 2021. Vol. 7, No 1. P. 76-87. (in Russ.)

(C) Novozhilova O. A., 2021

This is an open access article under the CC BY license (https://creativecommons.org/licenses/by/4.0/) 


\title{
Проблемы молодых инвалидов в Санкт-Петербурге: социологический анализ
}

\author{
О. А. Новожилова ${ }^{1}$
}

${ }^{1}$ Санкт-Петербургский государственный университет, Университетская набережная, 7-9, Санкт-Петербург, 199034, Российская Федерация

DOI: $10.18255 / 2412-6519-2021-1-76-87$

УДК 316

Научная статья

Полный текст на русском языке

Инвалидность как социальная проблема относится к числу наиболее актуальных явлений современного российского общества. В статье анализируются молодые инвалиды как специфическая социальная группа и проблемы, с которыми они сталкиваются в своей жизнедеятельности. Молодые инвалиды - это достаточно активная социальная группа, они участвуют в молодежных мероприятиях, раскрывают свои таланты. Но из-за барьеров в окружающей среде они не могут в полной мере реализовать себя. Проведено исследование, показывающее, какие проблемы молодых инвалидов требуют незамедлительного решения. Выявлены такие проблемы, как доступность медицинских услуг и лекарств, проблема трудоустройства, необорудованность транспорта и отсутствие безбарьерной окружающей среды, проблема получения образования и информационная доступность. Особенное внимание уделяется проблеме доступности как одному из факторов, препятствующих активному взаимодействию молодых инвалидов с окружающей средой. Лонгитюдный характер исследования позволил проанализировать, что изменилось в решении проблем данной социальной группы. Результаты исследования показали, что в Санкт-Петербурге и других городах стали гораздо больше уделять внимание этой категории людей, однако часто решение проблем все еще имеет точечный, а не комплексный характер.

Ключевые слова: инвалидность; молодые инвалиды; социальная политика; социальная проблема; социальная группа; доступная среда

ИНФОРМАЦИЯ ОБ АВТОРАХ

Новожилова, Ольга Алексеевна | E-mail: splinter91@mail.ru

Для цитирования: Новожилова О. А. Проблемы молодых инвалидов в Санкт-Петербурге: социологический анализ // Социальные и гуманитарные знания. 2021. Том 7, № 1. С. 76-87.

\section{Введение}

Люди с ограниченными возможностями здоровья рассматриваются прежде всего как социальная проблема и объект социальной помощи. На то, что является социальной проблемой, есть разные взгляды. В отечественной социологии происходит попытка совмещения традиционного подхода с теоретическим освоением социологии социальных проблем [1]. Инвалидность как социальная проблема относится к числу актуальных явлений современного российского общества, особенно в последнее время.

(C) Новожилова О. А., 2021

Статья открытого доступа под лицензией СС BY (https://creativecommons.org/licenses/by/4.0/) 
Проблемным полем данной статьи является изучение проблем молодых инвалидов как социальной группы. Выделение именно этой возрастной группы способствует более точному описанию проблем, характерных для нее. Многие из молодых инвалидов оценивают себя на равных с обычной молодежью, они активны и открыты для взаимодействия, участвуют в молодежных мероприятиях, раскрывают свои таланты. А некоторые стесняются статуса инвалидности, например, при поступлении в вуз. Поступают на общих основаниях, чтобы доказать себе и другим, что они такие же, как все. Таким образом, группа молодых инвалидов отличается от других возрастных групп. Эта статья ставит своей целью попытку проанализировать те проблемы, с которыми сталкиваются ежедневно молодые люди с инвалидностью, и показать необходимость их решения.

Актуальность данной темы обусловлена численностью инвалидов. В России насчитывается примерно 13 млн. инвалидов, молодых инвалидов - около 1 млн человек. В Санкт-Петербурге - 12533 человека [2]. Автор отмечает, что возрастной критерий молодых инвалидов - это 18-35 лет: нижняя граница обусловлена тем, что до 18 лет человек попадает в категорию «ребенок-инвалид», верхняя граница обусловлена законодательством РФ, согласно которому молодежью считается возраст до 30 лет, а в составе молодых семей - до 35 лет. Возрастной промежуток от 30 до 35 лет статистикой не учитывается. В настоящее время активно обсуждаются вопросы повышения возраста молодежи до 40 лет [3]. Таким образом, исходя из данных государственной статистики, достаточно сложно оценить точное число молодых инвалидов и решать проблемы этой социальной группы. И. Албегова подчеркивает, что «особым критерием выделения группы молодых инвалидов является наличие у молодого человека статуса инвалида, который определяется различными видами болезней» [4]. Так, в зависимости от степени тяжести заболевания можно выделить I, II или III группу инвалидности, а также различные степени ограничений трудоспособности. Например, инвалидность по общему заболеванию II или III группы внешне может никак не проявляться, поэтому люди с такими группами стараются не идентифицировать себя в качестве инвалидов. Некоторые молодые инвалиды стесняются своего статуса инвалида. Причиной этого является возможная стигматизации со стороны общества. Есть и обратная ситуация - люди озвучивают свой статус даже там, где в этом нет необходимости, с целью получить дополнительные возможные привилегии, поощряя особое отношение к себе. В этом случае можно говорить о социальном иждивенчестве. Таким образом, эта социально-возрастная группа является достаточно разнородной.

Степень научной разработанности проблемы инвалидности и ее основных аспектов насчитывает достаточно большое количество исследований. Так, в отечественной социологии и антропологии проблемы инвалидов изучали Е. Ярская-Смирнова, Э. Наберушкина, М. Муравьева, А. Клепикова, И. Утехин, П. Романов и ряд других. Однако исследований, объектом которых являются непосредственно молодые инвалиды, насчитывается мало. Среди российских авторов, занимающихся проблемами молодых инвалидов, можно выделить И. Ф. Албегову, Ф. Г. Албегова, И. С. Корешкову, О. М. Румянцеву, Т. Г. Ковкову, Ю. Н. Рюмину, но публикации этих авторов посвящены в большей степени реабилитации и технологиям социальной работы с молодыми людьми с ограниченными возможностями. Недостаточно приведен социологический анализ данной группы, не учтены ее особенности как объекта социальной и молодежной политики государства и ее возможности быть субъектом. 
В зарубежной социологии существует целое направление, посвященное концептуальному изучению инвалидности, - «disability studies». Среди авторов можно выделить Майка Оливера, Колин Барнс, Терезу Дегенер, Лена Бартона, Джонатана М. Левитта. Эти авторы рассматривают различные модели инвалидности, в том числе социальную и правозащитную, а также влияние этих моделей на социальную политику государства и жизнь самих инвалидов. Социология инвалидности за рубежом давно уже входит в перечень приоритетных направлений социального анализа. Отечественная социология только подбирается к анализу социальных проблем в контексте социологического дискурса, множество проблем инвалидности все еще изучены слабо или не изучены вовсе.

По словам Т. М. Симоновой, описывая состояние социальной проблемы, необходимо «анализировать ее в контексте системного подхода или концепции социокультурного поля, что позволит лучше понять причины возникновения проблемы и ее место в социальной жизни в целом» [5]. В современном контексте востребован подход, в котором подчеркивается ценность независимой жизни для каждого и для инвалидов в том числе. В основе данного подхода лежит социальная модель инвалидности, где инвалидность рассматривается как социальная проблема, решение которой заключается в обеспечении полной, равноправной интеграции человека с ОВЗ в общество. По словам Т. Дегенер, социальная модель инвалидности объясняет инвалидность как социальный конструкт через дискриминацию и притеснение [6]. Социальная модель различает физическое нарушение человека и непосредственно саму инвалидность. Первое относится к состоянию тела или разума, второе - это результат того, как окружающая среда и общество реагируют на это нарушение. Хьюз, Гудли и Дэвис писали, что «социальная модель оставалась довольно неумолимой со своим первоначальным пониманием и, что более важно ... со своей практической миссией, которая заключалась в устранении барьеров, блокирующих участие инвалидов в жизни общества» [7]. Речь идет о необходимости устранять все препятствия на пути взаимодействия инвалидов с обществом. Общество обязано адаптировать существующие в нем стандарты к особым нуждам людей, имеющих инвалидность, для того, чтобы они могли жить «независимой жизнью». Это прежде всего право человека быть неотъемлемой частью жизни общества и принимать активное участие в социальных, политических и экономических процессах, это свобода выбора и свобода доступа к жилым и общественным зданиям, транспорту, средствам коммуникации, страхованию, труду и образованию. Отметим, что главным препятствием для независимой жизни инвалидов остается представление о таких людях как о больных, нуждающихся в постоянной опеке, заботе и помощи, как о тех, «которых надо жалеть» и «которым чего-то не хватает». Исследование, освещенное в данное статье, покажет, насколько реализована концепция «независимой жизни» в Санкт-Петербурге, через анализ проблем, с которыми сталкиваются молодые инвалиды.

Целью статьи является социологический анализ положения молодых инвалидов, а также анализ проблем, с которыми они сталкиваются.

\section{Методы}

В марте - мае 2013 года автором было проведено исследование, целью которого являлось изучение качества социальной работы с молодыми инвалидами в Санкт-Петербурге. Анкетирование молодых людей с ограниченными возможностями в возрасте от 18 до 35 лет, проживающих в Санкт-Петербурге (N=90), проводилось на базе Профес- 
сионально-реабилитационного центра (ПРЦ), Центра социальной реабилитации Кировского района г. Санкт-Петербурга. Также была проведен фокусированный опрос в сети Интернет. Респондентам предлагалось пройти по ссылке и заполнить анкету.

В июле - августе 2020 года было принято решение повторить исследование, несколько расширив его в части вопросов, касающихся проблем, с которыми сталкиваются молодые инвалиды. Целью исследования было, во-первых, сравнить количественные показатели опроса и выявить произошедшие изменения, а во-вторых, выявить проблемы, с которыми сталкиваются молодые инвалиды в повседневной современной жизни. Гипотеза исследования - в настоящее время государство предпринимает все большее количество мер, направленных на улучшение качества жизни молодых инвалидов, поэтому проблем у молодых инвалидов должно быть меньше. В связи с условиями пандемии был проведен онлайн-опрос $(\mathrm{N}=70)$ среди инвалидов молодого возраста, проживающих на территории Санкт-Петербурга. Также было проведено интервью с экспертами - представителями органов власти, руководителями социальных учреждений, а также специалистами, непосредственно работающими с инвалидами $(\mathrm{N}=10)$.

\section{Результаты}

Результаты проведенного в 2013 году исследования показали, что среди основных проблем, с которыми чаще всего сталкиваются инвалиды, в том числе и молодые, следует назвать такие:

1. Проблема доступности лекарств и медицинских услуг

Так, треть всех опрошенных (29,9\%) сослалась на эту проблему. Как уже было сказано и раньше, доступность лекарств и медицинских услуг в г. Санкт-Петербурге оставляет желать лучшего. Основной причиной отсутствия доступности является дороговизна лекарственных препаратов или их редкость в наличии у аптек. То же самое касается медицинских услуг: основной проблемой является дороговизна, сопутствующей является отсутствие квалифицированных специалистов на местах.

2. Необорудованность транспорта

Так, пятая часть респондентов (20,5 \%) отметила эту проблему как ту, с которой они чаще всего сталкиваются. Городской общественный транспорт в большинстве своем не доступен для колясочников и маломобильных групп населения. На сегодняшний день ситуация изменилась.

3. Отсутствие доступных общественных мест и мест досуга (кино, театры и др.)

Многие респонденты (14,5 \%) указывали на то, что не могут посещать места досуга по двум причинам: физические препятствия (бордюры, барьеры и т. д.) на пути к учреждениям досуга и высокая стоимость билетов. Многие также указали на то, что не только места досуга недоступны, но и другие общественные места, такие как аптеки, магазины, дворы. Далеко не везде оборудованы пандусы или аппарели.

4. Доступность информации о возможностях для инвалидов, в том числе о правах и социальных услугах

Недоступна не только информация о социальных услугах. Например, респондентам предлагалось назвать причину, по которой они не могут заниматься спортом, в том числе паралимпийскими играми, получать реабилитацию, пользоваться льготами, социальным такси. И многие (13,7 \%) отметили, что не знают о льготах, которые они могут получать, об услуге «социальное такси», не участвуют в играх, т. к. не знают о месте 
их проведения, не знают о праве на бесплатную юридическую, психологическую помощь. Не все знают, куда можно пойти учиться после окончания коррекционной школы. Многие не знают даже, куда обратиться за данной информацией.

Таким образом, мы видим, что на первый план выходит проблема лекарств и медицинских услуг, на втором месте проблемы с доступностью транспорта, далее доступность информации и общественных мест, затем доступность информации о возможностях для инвалидов, в том числе о правах и социальных услугах.

В сравнении с этими результатами исследование 2020 года выявило некоторые сходства и различия. Так, на первом плане осталась проблема недоступности медицинских услуг и отсутствие или высокая стоимость лекарств. Все больше людей говорят об отсутствии возможности приобретения необходимых лекарств, 26,1% респондентов жалуются на эту проблему. При этом мнения людей разделились пополам: одни пожаловались на отсутствие необходимых лекарств в аптеке, и столько же людей отметило дороговизну и невозможность из-за этого купить лекарства. Действительно, для инвалидов эта проблема остается актуальной, несмотря на то, что локация опроса - г. СанктПетербург с развитым уровнем жизни и логистикой. Многие лекарства сложно найти в аптеках. К таким относятся лекарства, необходимые для пациентов с редкими орфанными болезнями. Их стоимость доходит до нескольких миллионов рублей за единицу, причем терапия чаще всего нужна в течение всей жизни человека. Конечно, среднестатистическая российская семья не может себе позволить такого лечения.

Следующей важной проблемой является отсутствие доступной окружающей среды - доступной транспортной инфраструктуры (13\% отметили эту проблему) и безбарьерной среды в общественных местах (15,9 \% указали наличие данной проблемы). Различные болезни накладывают те или иные ограничения на жизнедеятельность молодых людей, на их взаимодействие с окружающей средой. Автору представляется, что наиболее трудно взаимодействие с городской средой будет осуществляться у молодых людей с нарушениями опорно-двигательного аппарата, зрения, слуха и с умственными нарушениями. Трудности возникают в преодолении барьеров, с которыми сталкиваются люди с указанными видами нарушений в повседневной жизни, как физическими, так и психологическими. Так, если для инвалидов, передвигающихся на кресле-коляске, необходимо устранение только физических барьеров, то для инвалидов с нарушением зрения необходимо устранить физические и информационные барьеры на пути движения, предоставление информации в доступном виде. Это будет успешным шагом на пути взаимодействия инвалидов с окружающей средой. Работа в этом направлении ведется, но пока далека от того момента, когда мы можем сказать, что хотя бы 80 \% от общей численности данных категорий инвалидов могут свободно выйти из дома и посетить любое учреждение. Кроме того, на сегодняшний день можно столкнуться с абсурдными ситуациями, когда доступная среда создается «для галочки». Достаточно мест, где к пандусу не подъехать из-за бордюрного камня, лежащего перед ним, или же пандус упирается в стену или забор. Тактильная плитка для слепых уложена неправильно или ведет непосредственно на препятствие. Это говорит об отсутствии компетентных специалистов, занимающихся данными вопросами, о халатности исполнителей. Существует специальная комиссия по доступной среде, которая принимает объект совместно с его руководителем. Комиссия указывает на недочеты, если они есть, составляет акт обследования. Однако бюрократический формат процедур исправления недочетов может занять от двух до пяти лет в зависимости от вида работ. Если недочеты выявлены в государственной организации, то ей снова 
необходимо делать проектно-сметную документацию, искать подрядчика через процедуру аукциона, начинать работы. К этому времени, по опыту одного из учреждений, поменялся нормативно-правовой акт (к примеру, СНиП 59.13330.2016) ${ }^{1}$, и снова у готового объекта имеются недочеты в соответствии с новым нормативно-правовым документом. Если недочеты выявлены у негосударственной организации, то реалии таковы, что организации проще заплатить штраф, чем что-то исправлять. Таким образом, в сегодняшней системе создания безбарьерной среды есть и определенные организационные проблемы, требующие внимания специалистов и совместного поиска решений. На рисунке 1 представлена сравнительная диаграмма результатов исследований 2013 и 2020 гг.

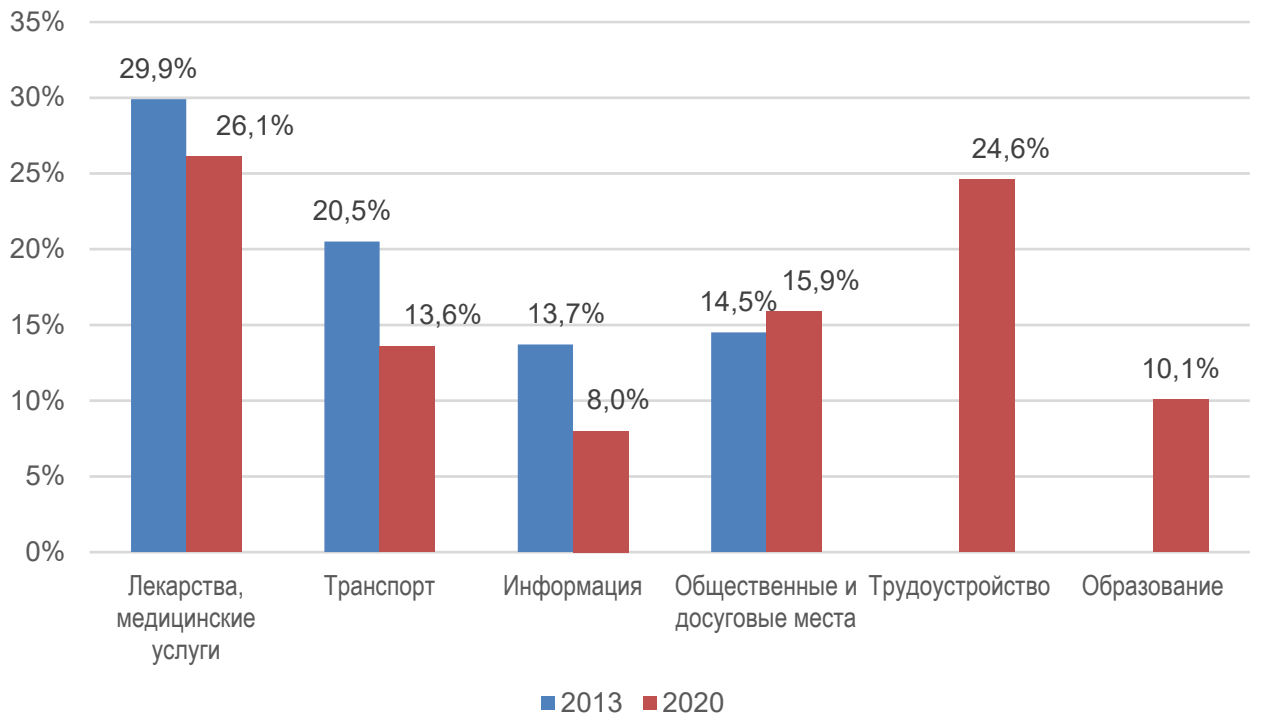

Рисунок 1. Проблемы молодых инвалидов. Сравнительная диаграмма результатов исследований 2013 и 2020 гг.

Как уже было сказано, в 2020 году исследование несколько расширили, добавив в него две важные сферы жизни - образование и трудоустройство. Из полученных данных выяснилось, что проблема трудоустройства является второй наиболее значимой проблемой, с которой сталкиваются молодые инвалиды в Санкт-Петербурге. Как видно на рисунке 1, на эту проблему сослались почти четверть опрошенных (24,6 \%). Следует здесь отметить, что респондентам также предлагалось ответить на вопрос о выборе: предпочтительнее увеличение льгот и пособий или же возможность трудиться и зарабатывать деньги самим. 43,8 \% выбрали повысить возможность трудоустройства, остальные же (56,2 \%) отдали предпочтение увеличению пособий, из которых 7 \% работают и место работы их устраивает (то есть пособие они рассматривают как дополнительный источник дохода и предлагают его увеличить), остальные не работают.

\footnotetext{
${ }^{1}$ СП 59.13330.2016 Доступность зданий и сооружений для маломобильных групп населения. Актуализированная редакция СНиП 35-01-2001 // Электронный фонд правовой и нормативно-технической документации «Кодекс». 15.05.2017. URL: http://docs.cntd.ru/document/456033921 (дата обращения: 31.08.2020)
} 
К сожалению, в работе с инвалидами, в том числе молодыми, специалисты сталкиваются с низкой мотивацией к труду. Примером низкой мотивации является неудачный опыт профессиональной реабилитации, которую осуществляют на базе одного из центров социальной реабилитации. Специалисты совместно с инвалидами посещают различные ярмарки вакансий, осуществляют взаимодействие с районной службой занятости, помогают инвалидам трудоустроиться. Однако, спустя некоторое время (как правило, 1-2 месяца), инвалиды увольняются и возвращаются на социальное обслуживание в центр. Причинами подобного социального поведения являются как недостаточная работа по мотивации клиентов со стороны сотрудников, так и отсутствие условий для комфортной работы на местах, несовпадение ожиданий с реальностью. Таким образом, уровень занятости и экономической активности инвалидов остается на крайне низком уровне. И. Корешкова также отмечает, что основной проблемой для молодых инвалидов остается занятость [8]. Автор согласен с данным мнением о необходимости создания новых форм занятости, таких как участие в разработке и реализации социальных проектов и программ. Политика государства в направлении занятости, как правило, сводится к квотированию рабочих мест и профессиональной реабилитации.

На проблему получения образования сослались 10,1 \% опрошенных (рис. 1). Согласно Федеральному закону 181-ФЗ от 24.11.1995 «0 социальной защите инвалидов в Российской Федерации» ${ }^{1}$, инвалиды имеют право на получение образования, образовательные организации предоставляют инвалидам льготные условия поступления. Многие инвалиды пользуются этим правом, некоторые даже отказываются от этой возможности, чтобы доказать себе, что они могут поступить наравне со всеми. Однако для большинства граждан с ограниченными возможностями здоровья получение образования остается недоступным. И дело даже не в образовательных организациях, хотя безбарьерная среда есть далеко не в каждом образовательном учреждении. А в том, что инвалидам просто не добраться до места учебы. Отсутствие доступной городской среды для молодых людей с инвалидностью влияет на возможность получить полноценное образование. Работая в одном из центров реабилитации, автор отмечает, что ряд молодых людей выражал желание получить среднее профессиональное образование в Профессионально-реабилитационном центре. В настоящее время это единственное профильное образовательное учреждение среднего профессионального образования для людей с инвалидностью и ослабленным здоровьем в Санкт-Петербурге. Однако его расположение доступно далеко не всем желающим. Молодые инвалиды, проживающие в Кировском, Красносельском, Петродворцовом и ряде других районов, не могут самостоятельно добраться до Центра. С. Филлипс также отмечает, что «отсутствие доступного пространства ограничивает возможности людей продолжать обучение на всех уровнях, от начальной школы до высшего образования, а также ограничивает возможности трудоустройства и осуществления социальной, культурной, спортивной и рекреационной деятельности» [9], поэтому создание комфортной и доступной городской среды является одним из важных условий комфортной жизнедеятельности инвалидов в обществе. Сейчас набирает популярность дистанционное обучение, что для молодых людей с инвалидностью является очень важным. Отчасти такой метод поможет решить данную проблему, но, с другой стороны, инвалиды снова окажутся в социальной изоляции.

\footnotetext{
1 Федеральный закон от 24.11.1995 № 181-Ф3 «О социальной защите инвалидов в Российской Федерации» //Электронный фонд правовой и нормативно-технической документации «Кодекс». 24.04.2020. URL: http://docs.cntd.ru/document/ 9014513 (дата обращения: 02.09.2020)
} 
Говоря о проблемах инвалидности, следует упомянуть еще о такой проблеме, как социальная изоляция, неготовность российского общества «принять» нетипичного человека. Несмотря на то, что, по данным исследований, люди стали чаще видеть инвалидов на улицах города, проблема до сих пор актуальна [10]. В книге «Обратная сторона Луны, или что мы не знаем об инвалидности: теория, репрезентации, практики» в интервью с инвалидами представлены показательные примеры того, как людям с инвалидностью порой бывает сложно преодолеть себя и выйти из дома. Многие, как, например, Александр, стесняются своего вида и ждут вечера, чтобы просто выйти из дома и прогуляться на свежем воздухе. Или пример с Юлией: когда мероприятие подготовлено для молодых инвалидов, но при этом должного информирования не получило. «Хорошо, говорят, поехали. Я обзвонила всех своих друзей, вот этих ребят на колясках из ..., приглашали ли кого-то еще. Нет, говорят. Я туда приехала, но это, конечно, зрелище печальное, там в основном были одни пожилые люди и никого не было молодых. А нас очень много, ребят, которые активные, стремятся, многие работают в Интернете» [11]. Развиваются НКО, создаются различные клубы, проводятся различные мероприятия, но, несмотря на это, проблема социальной изолированности остается.

Следует отметить, что представители власти и специалисты, работающие с молодыми людьми с ограниченными возможностями, также считают, что качество социализации инвалидов оставляет желать лучшего. Из интервью с экспертами следует, что работа в данных направлениях ведется, но на сегодняшний день ее недостаточно, и качество исполнения оставляет желать лучшего. «Работа в городе по обеспечению социальной поддержки, насколько я знаю, ведется во всех направлениях, - сообщает С. А. Тимонов, директор Профессионально-реабилитационного центра, - отторгаемых тем в городе в принципе нет, другое дело, что кое-что надо побыстрее делать». Что касается доступности информации для инвалидов, то, по словам директора, если человек мотивирован, он найдет информацию за несколько минут по нескольким каналам: по общественным организациям, в которых, как правило, состоят инвалиды, по районным отделам социальной защиты населения и в социальных сетях.

Противоположной точки зрения придерживается директор Центра социальной реабилитации инвалидов и детей-инвалидов Кировского района Ю.А.Шепелев. Он считает, что информации о социальных услугах в нашем городе довольно мало. «Нет, никакой информации инвалиды не получают, а доступность информации становится все меньше. Если раньше по телевизору была социальная реклама, то сейчас этого ничего нет, есть, конечно, социальный канал нашего Кировского района, но это, опять же, может позволить себе далеко не каждый, ведь это кабельный канал. А так, листовки, программки - это все разовое, хотелось бы, конечно, больше социальной рекламы». Похожего мнения придерживается С. В. Лучиц, начальник отдела социальной защиты населения Администрации Петродворцового района: «Информации о представляемых социальных услугах недостаточно. Сегодня, для того чтобы информация о предоставляемых услугах дошла до нуждающихся в ней инвалидов - социальные службы вынуждены заниматься саморекламой. Это средства массовой информации, кабельное телевидение, изготовление и распространение информационных листовок, буклетов в учреждениях здравоохранения и образования. Данная информация доступна, но в связи с ограниченностью бюджетного финансирования на изготовление информационных материалов - недостаточна. Отмечу, что в нашем районе работа в этом направлении ведется. Создано районное бюро социальных участковых, которые призваны оказывать адресную помощь». 
Что касается в целом социального положения молодых людей с ограниченными возможностями в России, то мнения экспертов также расходятся. По словам С. В. Лучиц, «социальное положение молодых людей с ограниченными возможностями в РФ довольно стабильное. Действующее законодательство РФ в сфере социальной защиты предусматривает достаточное количество различных мер социальной поддержки и социальных гарантий для данной целевой группы».

Однако, по мнению руководителя отдела социально-психологической реабилитации и медицинского сопровождения ПРЦ И. В. Светличной, «социальное положение молодых инвалидов в РФ неважное, новая редакция законов учитывает не все потребности инвалидов и нуждается в доработке».

На вопрос о том, должны ли инвалиды учиться и работать в обществе или отдельно от него, эксперты единогласно поддержали первый вариант ответа. Наиболее полный ответ дала С. В. Лучиц: «Молодые люди с инвалидностью должны учиться и работать в обществе, однако для их обучения должны быть обеспечены все условия. Однако до настоящего времени большей проблемой остается отсутствие доступной среды жизнедеятельности для инвалидов, то есть как инвалид от места проживания доберется до места обучения и насколько комфортно будет проходить обучение на общих условиях. В связи с этим для создания необходимых условий для инвалидов возможно создание специализированных, но не закрытых учреждений».

Таким образом, мнения экспертов в этих вопросах расходятся, но в одном они точно уверены: социальная политика в России должна быть направлена в том числе на развитие человеческого потенциала молодых людей с инвалидностью, на социальную реабилитацию и поддержку инвалидов.

\section{Обсуждение}

На основании проведенного анализа можно сделать вывод о том, что понятие «молодые инвалиды» выходит за пределы сложившихся рамок анализа инвалидности, не выделяется в статистических данных и, как следствие, не учитывается или учитывается не в полной мере в практической работе государственных учреждений. Проблемы молодых инвалидов как социальной группы требуют комплексного решения с сохранением индивидуального подхода. Справедлива фраза Олега Колпащикова, незрячего бизнес-тренера из Екатеринбурга, одного из организаторов проекта «Белая трость» о помощи инвалидам: «Если ты по-настоящему хочешь помочь инвалиду, подумай, чему ты можешь у него научиться» [12]. Возможно, именно с этой позиции стоит смотреть на проблемы молодых инвалидов. Логика проста: когда мы учимся у других людей, мы смотрим на них с уважением, с заинтересованностью, а не с сочувствием и жалостью. Почувствовать себя равным с другими, равным в социальном плане особенно важно для молодого человека с инвалидностью.

Подводя итоги, отметим еще раз, что к основным проблемам молодых инвалидов можно отнести доступность медицинских услуг и лекарств, проблему трудоустройства, необорудованность транспорта и отсутствие безбарьерной окружающей среды, проблему получения образования и информационной доступности. Кроме того, многие исследователи отмечают социальную изоляцию как еще одну проблему людей с инвалидностью.

Проведенный анализ также свидетельствует о том, что в Санкт-Петербурге проблемам инвалидов стали больше уделять внимания. К примеру, проблемой, связанной с доступностью лекарств, занялись на федеральном уровне. Усилиями НКО и сотрудников медицинских организаций удалось добиться небольшого прогресса в этой сфере. 
Так, директор фонда «Семьи СМА» Ольга Германенко отмечает, что удалось добиться как снижения стоимости лекарств для лечения больных с СМА (спинально-мышечной атрофией) за счет его включения в список жизненно необходимых и важнейших лекарственных препаратов, так и создания Фонда поддержки детей с редкими заболеваниями. Пока механизм, с помощью которого дети с редкими заболеваниями будут получать необходимое лечение, неизвестен, а список болезней, при которых лекарства отпускаются бесплатно, не достаточно полный. Однако факт того, что небольшие шаги сделаны, позволяет говорить о внимании государства к вопросу доступности лекарств для молодых инвалидов.

Также власти обратили внимание на проблему доступности информации. Если в 2013 году это была одна из актуальных проблем, то сейчас мои исследования показали, что актуальность проблемы доступности информации существенно снизилась. На сегодняшний день проводятся кампании по информированию граждан о предоставлении различных социальных услуг, адресной социальной помощи, информирование о льготах. Достаточно информации представлено в сети Интернет. С 2019 года в СанктПетербурге создана служба социальных участковых с целью оказания беззаявительной помощи. Заявительный принцип оказания помощи оказался недостаточно эффективным, поскольку не выявляет всех нуждающихся. Служба социальных участковых призвана осуществлять помощь адресно, в том числе на дому.

В целом по проблеме доступной окружающей среды в городе отмечаются существенные изменения. Так, доступность транспортной системы улучшена, показатель по этой проблеме снизился с 20,5 \% до 13,6 \% (рис. 1). Сегодня городские автобусы оснащены пандусами, в метро работает служба сопровождения. Многие объекты социальной инфраструктуры приспособлены под нужды инвалидов. Отметим, что доступная среда - это возможность молодых инвалидов быть независимыми экономическими субъектами, активно участвовать в политической, культурной и социальной жизни общества. Этот показатель, с одной стороны, отражает уровень реализации их прав как граждан социального государства, с другой - демонстрирует уровень развития государства и общества.

На сегодняшний день имеются проблемы с надлежащим исполнением законодательных актов. Различные субъекты трактуют нормативно-правовые документы поразному. Так, например, в связи с ратификацией Россией Конвенции о правах инвалидов в 2012 году в ряд нормативных документов были внесены значительные изменения. В частности, Ф3 419 «0 внесении изменений в отдельные законодательные акты» 1 затронул вопросы доступности городского пространства для инвалидов. Но проведенное исследование показывает, что исполнение на местах оставляет желать лучшего. Бюрократический механизм реализации и некомпетентность специалистов тормозят развитие доступности городской среды в регионе. Немаловажным является тот фактор, что ответственность за создание доступной среды возложена на один орган власти - Министерство труда и социальной защиты в РФ и Комитет по социальной политике Санкт-Петербурга. Тогда как решение данной задачи должно носить комплексный характер, с привлечением специалистов не только из социальной сферы.

\footnotetext{
${ }^{1}$ Федеральный закон от 01.12.2014 № 419-Ф3 «О внесении изменений в отдельные законодательные акты Российской Федерации по вопросам социальной защиты инвалидов в связи с ратификацией Конвенции о правах инвалидов» // Электронный фонд правовой и нормативно-технической документации «Кодекс». 29.12.2015. URL: http://docs.cntd.ru/document/ 420236204 (дата обращения: 02.09.2020)
} 
Но несмотря на имеющиеся проблемы, автор отмечает, что Санкт-Петербург достиг определенных результатов в политике, направленной на решение проблем молодых инвалидов. Постепенно качество жизни данной социальной группы меняется в лучшую сторону. Государство должно способствовать трансформации общественного сознания, формированию политики на основе социальной модели инвалидности, а значит, необходимо приложить еще немало сил для достижения поставленных целей и решения проблем молодых инвалидов.

\section{Ссылки / References}

1. Симонова Т. М. Интегративный подход к исследованию социальных проблем // Журнал социологии и социальной антропологии. 2009. Том 12. № 1. С. 66-74.

2. Численность инвалидов по возрастным группам в разрезе субъектов РФ // Федеральная государственная информационная система «Федеральный реестр инвалидов». 20.11.2020. URL: https://sfri.ru/analitika/chislennost/chislennost/chislennost-po-vozrastu?territory=1 (дата обращения: 31.08.2020).

3. Чуй Ю. В. Особенности и специфика ценностных ориентаций российской молодежи // Вестник социально-политических наук. 2015. № 14. С. 44-46.

4. Албегова И. Ф., Корешкова И. С. Молодые инвалиды как социальная группа и объект социальной работы // Социальные и гуманитарные знания. 2017. Том 3. № 1. С. 50-54.

5. Симонова Т. М. Структура социальной проблемы и ее анализ // Вестник ЧелГУ. 2009. № 18. URL: https://cyberleninka.ru/article/n/struktura-sotsialnoy-problemy-i-ee-analiz (дата обращения: 09.09.2020).

6. Degener T. A human rights model of disability // Researchgate.net. 31.12.2014. URL: https://www.researchgate.net/publication/283713863_A_human_rights_model_of_disability (date of access: 17.08.2020).

7. Hughes B., Goodley D., Davis L. Conclusion: Disability and Social Theory // In Disability and Social Theory: New Developments and Directions, edited by D. Goodley, B. Hughes and L. Davis. Basingstoke: Palgrave Macmillan, 2012. P. 317.

8. Корешкова И. С. Молодые инвалиды как группа современной российской молодежи и ее проблемы в меняющемся мире // Уральский Федеральный университет. 18.03.2016. URL: http://elar.urfu.ru/bitstream/10995/81617/1/978-5-91416-007-1_2016-233.pdf (дата обращения: 02.09.2020).

9. Филлипс С. Параллельный мир // Обратная сторона Луны, или что мы не знаем об инвалидности: теория, репрезентации, практики: сб. статей / отв. ред: А. С. Курленкова, Е. Э. Носенко-Штейн. М.: Издательство МБА, 2018. С. 223-274.

10. Романов П. В., Ярская-Смирнова Е. Р. Инвалиды и общество: двадцать лет спустя // Социологические исследования. 2010. № 9. С. 50-58.

11. Истории жизни // Обратная сторона Луны, или что мы не знаем об инвалидности: теория, репрезентации, практики: сб. статей / Отв. ред: А. С. Курленкова, Е. Э. Носенко-Штейн. М.: Издательство МБА, 2018. С. 381-419.

12. Михнова И. Пространство возможностей. Заметки на полях библиотечного дела. Сборник полемических статей. М.: Российская государственная библиотека для молодёжи, 2017. $120 \mathrm{c}$. 